\title{
Atypical Werner syndrome
}

INSERM

\section{Source}

INSERM. (1999). Orphanet: an online rare disease and orphan drug data base. Atypical Werner syndrome. ORPHA:79474

Atypical Werner syndrome refers to a heterogeneous group of cases that are clinically diagnosed as Werner syndrome (WS; see this term) but do not carry WRN gene mutations. Similar to classical WS caused by WRN mutations, patients generally exhibit an aged appearance and common age-related disorders at earlier ages compared to the general population. 